Polymer Journal, Vol. 39, No. 8, pp. 777-782 (2007)

(C) 2007 The Society of Polymer Science, Japan

\title{
Synthesis of Poly( $N$-fluoroalkyl benzamide) with Controlled Molecular Weight and Polydispersity Index
}

\author{
Kaoru OHShIMIzU, Yuji ShIBASAKI, ${ }^{\dagger}$ and Mitsuru UedA \\ Department of Organic and Polymeric Materials, Graduate School of Science and Engineering, \\ Tokyo Institute of Technology, 2-12-1 O-okayama, Meguro-ku, Tokyo 152-8552, Japan
}

(Received February 21, 2007; Accepted April 28, 2007; Published June 19, 2007)

\begin{abstract}
Poly( $N$-fluoroalkyl benzamide) (4) with a controlled molecular weight (MW) and a polydispersity index (PDI) was prepared by chain-growth polycondensation of 4-( $N-1,1,1,2,2,3,3,4,4,5,5,6,6$-tridecafluorooctylamino) benzoylbenzoxazolin-2-thione (3) initiated with $p$-nitrobenzoyl chloride using EtMgBr as an activator. The $\mathrm{MW}$ of 4 was tailored up to 25,000 by changing the feed ratio of the monomer and the initiator, while the PDI was maintained below 1.2. A $10 \%$ weight loss and a glass transition temperature of 4 were $380^{\circ} \mathrm{C}$ and $92{ }^{\circ} \mathrm{C}$ in nitrogen, respectively. A contact angle of the polymer film against a water droplet was 105.0, which was higher than 91.0 for poly $(N$-octyl benzamide), indicating monomer $\mathbf{3}$ could be applicable to prepare a novel amphiphilic block copolymer.

[doi:10.1295/polymj.PJ2006243]

KEY WORDS Chain-growth Polycondensation / Polyamide / Controlled Polymerization / $N$-Fluoroalkyl / Contact Angle /
\end{abstract}

A variety of methods to realize nanoscopic-segregated structures have been developed, and such nano-materials are now applied to coatings, electronic devices, medicines, composites, and paintings. ${ }^{1}$ Block copolymerization is one of the most powerful tools to realize such materials because over hundreds of materials can be designed and prepared by this method. ${ }^{2}$ Living polymerization is generally used to obtain a well-defined block copolymer, ${ }^{3}$ but this is only for addition polymerization monomers. Molecular weights (MWs) and the polydispersity indices (PDIs) of condensation block copolymers are generally difficult to control although there are strong demands from various fields such as the synthesis of thermoplastic elastomers. ${ }^{4}$ Recently, a novel strategy to control the MW and PDI in condensation polymers were postulated and experimentally verified by the chain-growth polycondensation of aminobenzoic acid derivatives, ${ }^{5}$ 4hydroxyphenyl-4'-fluorophenylsulfone, ${ }^{6}$ and 4-hydroxyphenyl-4'-fluorophenylketon. ${ }^{7}$ This technique was applied to the preparation of well-defined condensative block copolymers such as poly $(p-N$-alkylbenzamide)- $b$-poly(p-benzamide) ${ }^{8}$ poly( $p$-benzamide)- $b$ poly $(m$-benzamide $),{ }^{5 c}$ polyarylate with different side chains, ${ }^{9}$ and poly(3-alkylthiophene) with different side chains. ${ }^{10}$

Fluorine-containing polymers are used in a variety of high performance applications such as separation membranes, coatings, photoresists, and medical materials due to their outstanding properties such as high heat and chemical resistance, good antiweatherbility,
UV-stability, low surface energies, low water absorption, good dielectric and optical properties. ${ }^{11}$ A twophase graft copolymer consisting of fluoro- and nonfluorinated units is expected to show good miscibility with each homopolymer and excellent surface properties; thus the polymers have attracted particular attention in the fields of surface modification of various polymers. We have also reported a novel chain-growth polycondensation of 4- $\mathrm{N}$-octylaminobenzoic acid derivative. Thus, the investigation of chain-growth polycondensation of $\mathrm{N}$-fluoroalkylbenzoic acid is of importance for the building block of a novel amphiphilic block copolybenzamide with fluorine and non-fluorine units. The goal of this research was to synthesize a well-defined $N$-fluoroalkyl polyamide with the controlled MW and PDI. This novel type polyamide would be useful to design a variety of block copolymers, which could be applicable to design an engineering plastic with phase-separated structure in it.

\section{EXPERIMENTAL}

\section{Materials}

Tetrahydrofuran (THF) was dried over sodium and distilled before use under nitrogen. Diphenyl(2,3-dihydro-2-thioxo-3-benzoxazolyl)phosphonate (DBOP) was kindly donated from KYOCERA Chemical, and recrystallized from hexane before use. Lithium chloride was dried at $180^{\circ} \mathrm{C}$ for $2 \mathrm{~h}$ under reduced pressure and used under nitrogen. All other reagents and solvents were used without further purification.

${ }^{\dagger}$ To whom correspondence should be addressed (Tel/Fax: +81-3-5734-2126, E-mail: yshibasa@ polymer.titech.ac.jp). 


\section{Measurements}

FT-IR spectra were measured on a Horiba FT-720 spectrometer. ${ }^{1} \mathrm{H}$ and ${ }^{13} \mathrm{C}$ NMR spectra were recorded with a Bruker DPX300S spectrometer. Number- and weight-average molecular weights $\left(M_{\mathrm{n}}\right.$ and $\left.M_{\mathrm{w}}\right)$ were measured by gel permeation chromatography (GPC) on a Jasco GULLIVER 1500 system equipped with a polystyrene gel column (Plgel $5 \mu \mathrm{m}$ MIXED-C) eluted with $\mathrm{CHCl}_{3}$ at a flow rate of $1.0 \mathrm{~mL} \mathrm{~min}^{-1}$ calibrated by standard polystyrene samples. Preparative high pressure liquid chromatography (HPLC) was performed with a Japan Analytical Industry LC-908 equipped with two consecutive gel columns, JAIGELs $1 \mathrm{H}$ and $2 \mathrm{H}$, detected with refractive index and ultraviolet at $254 \mathrm{~nm}$ using chloroform as an eluent with a flow rate of $3.8 \mathrm{~mL} \mathrm{~min}^{-1}$. Thermal analysis was performed on a Seiko EXSTAR 6000 TG/DTA 6300 thermal analyzer at a heating rate of 10 ${ }^{\circ} \mathrm{C} / \mathrm{min}$ for thermogravimetry (TG) and a Seiko EXSTAR 6000 DSC 6200 at a heating rate of 10 ${ }^{\circ} \mathrm{C} / \mathrm{min}$ for differential scanning calorimetry (DSC) under nitrogen.

The films for contact angle measurements were prepared by spin-coating (4000 rpm, 20s) onto cover glasses from $2.6 \mathrm{wt} \% \mathrm{THF}$ solution of the polymers. The samples were dried at $25^{\circ} \mathrm{C}$ for $24 \mathrm{~h}$ and annealed at $100{ }^{\circ} \mathrm{C}$ for $4 \mathrm{~h}$ under vacuum to allow the polymer chains to reach their equilibrium configurations. Contact angles using water droplets were measured with Kyowa Interface Science CA-A. The film thickness was around $500 \mathrm{~nm}$, evaluated by Dektak surface profiler.

Synthesis of 4-(N-1,1,1,2,2,3,3,4,4,5,5,6,6-tridecafluorooctylamino)benzoic acid ethylester (1)

Into a flask containing 4-aminobenzoic acid ethyl ester $(25.0 \mathrm{~g}, 165 \mathrm{mmol})$ were placed $1,1,1,2,2,3,3,4,4$, 5,5,6,6-tridecafluoroiodeoctane $(25.0 \mathrm{~g}, 51.0 \mathrm{mmol})$ and hexamethylphosphoramide (HMPA) (35 mL) under nitrogen. The reaction mixture was heated at $130{ }^{\circ} \mathrm{C}$ for $4 \mathrm{~h}$, and poured into water $(300 \mathrm{~mL})$. The precipitate was collected, washed with water/methanol (1:1 in volume), and recrystallized from methanol to give white needles $(20.8 \mathrm{~g}, 85 \%$ yield). M.p. 87.4$87.7^{\circ} \mathrm{C}$; IR (KBr) v $3375(\mathrm{~N}-\mathrm{H}), 1678(\mathrm{C}=\mathrm{O}), 1604$ (aromatic C-H) cm ${ }^{-1} ;{ }^{1} \mathrm{H} \mathrm{NMR}\left(\mathrm{CDCl}_{3}, 25^{\circ} \mathrm{C}\right) \delta$ $1.37\left(\mathrm{t}, 3 \mathrm{H}, \mathrm{CH}_{2}-\mathrm{CH}_{3}, \mathrm{~J}=7.2 \mathrm{~Hz}\right), 2,42(\mathrm{~m}, 2 \mathrm{H}$, $\left.\mathrm{CH}_{2}-\mathrm{CH}_{2}\right), 3.60\left(\mathrm{~m}, 2 \mathrm{H}, \mathrm{N}-\mathrm{CH}_{2}\right), 4.23$ (s, 1H, N-H), $4.32\left(\mathrm{~m}, 2 \mathrm{H}, \mathrm{O}-\mathrm{CH}_{2}\right), 6.58(\mathrm{~d}, 2 \mathrm{H}, \mathrm{Ar}-\mathrm{H}, \mathrm{J}=8.7$ $\mathrm{Hz}), 7.91$ (d, 2H, Ar- $H, \quad \mathrm{~J}=8.7 \mathrm{~Hz}) ;{ }^{13} \mathrm{C}$ NMR $\left(\mathrm{CDCl}_{3}, 25^{\circ} \mathrm{C}\right) \delta 14.8,30.9,35.8,60.7,111.9,120.1$, 132.0, 151.0, $167.0(\mathrm{C}=\mathrm{O})$; Elemental Anal. Calcd for $\mathrm{C}_{17} \mathrm{H}_{14} \mathrm{~N}_{2} \mathrm{O}_{2} \mathrm{~F}_{13}$ : C; 39.94, H; 2.76, N; 2.74, F; 48.31. Found: C; 39.87, H; 3.01, N; 2.96, F; 47.67.
Synthesis of 4 - $(N-1,1,1,2,2,3,3,4,4,5,5,6,6$-tridecafluorooctylamino)benzoic acid (2)

Into a flask containing $1(21.0 \mathrm{~g}, 41.0 \mathrm{mmol})$ were placed potassium hydroxide $(43 \mathrm{~g}, 770 \mathrm{mmol})$ and methanol $(300 \mathrm{~mL})$ under nitrogen. The reaction mixture was heated at $65^{\circ} \mathrm{C}$ for $6 \mathrm{~h}$, and the solution was acidified around $\mathrm{pH} 4$ with concentrated hydrogen chloride. The precipitate was collected, washed with water, and recrystallized from methanol to give a white curdy (16 g, $83 \%$ yield). M.p. $172.5-174.5^{\circ} \mathrm{C}$; IR (KBr) v $3440(\mathrm{~N}-\mathrm{H}), 2500-3000(\mathrm{COOH}), 1674$ $(\mathrm{C}=\mathrm{O}), \quad 1604 \quad$ (aromatic $\mathrm{C}-\mathrm{H}) \quad \mathrm{cm}^{-1} ;{ }^{1} \mathrm{H}$ NMR $\left(\mathrm{CDCl}_{3}, 25^{\circ} \mathrm{C}\right) \delta 2,44\left(\mathrm{~m}, 2 \mathrm{H}, \mathrm{CH}_{2}-\mathrm{CH}_{2}\right), 3.62(\mathrm{t}$, $\left.2 \mathrm{H}, \mathrm{N}-\mathrm{CH}_{2}, \mathrm{~J}=6.9 \mathrm{~Hz}\right), 4.32(\mathrm{~s}, 1 \mathrm{H}, \mathrm{N}-\mathrm{H}), 6.60$ (d, $2 \mathrm{H}, \quad \operatorname{Ar}-H, \mathrm{~J}=8.7 \mathrm{~Hz}), 7.96(\mathrm{~d}, 2 \mathrm{H}, \operatorname{Ar}-H, \mathrm{~J}=$ $9 \mathrm{~Hz}) ;{ }^{13} \mathrm{C} \mathrm{NMR}\left(\mathrm{CDCl}_{3}, 25^{\circ} \mathrm{C}\right) \delta 30.1,35.2,111.8$, 118.9, 132.0, 152.5, $168.3(\mathrm{C}=\mathrm{O})$; Elemental Anal. Calcd for $\mathrm{C}_{15} \mathrm{H}_{10} \mathrm{~N}_{1} \mathrm{O}_{2} \mathrm{~F}_{13}$ : C; 37.28, H; 2.09, N; 2.90, F; 51.11. Found: C; 37.23, H; 2.02, N; 2.97, F; 51.19.

Synthesis of 4-(N-1,1,1,2,2,3,3,4,4,5,5,6,6-tridecafluorooctylamino) benzoylbenzoxazolin-2-thione (3)

Into a solution of $4-(N-1,1,1,2,2,3,3,4,4,5,5,6,6-$ tridecafluorooctilamino)benzoic acid $(0.483 \mathrm{~g}, 1.00$ mmol) and triethylamine $(0.16 \mathrm{~mL}, 1.10 \mathrm{mmol})$ in $N$ methyl-2-pyroridone (NMP) $(1 \mathrm{~mL})$ was added DBOP $(0.422 \mathrm{~g}, 1.10 \mathrm{mmol})$ at $25^{\circ} \mathrm{C}$, and the reaction was continued at $50^{\circ} \mathrm{C}$ for $5 \mathrm{~h}$. The resulting solution was pored into $3 \mathrm{wt} \%$ sodium bicarbonate aqueous solution, and the precipitate was collected, dissolved with ethyl acetate, dried over magnesium sulfate, concentrated, and recrystallized (ethyl acetate/hexane $1 / 5$ in volume $)$ to give yellow crystals $(0.34 \mathrm{~g}, 55 \%$ yield). M.p. $110-112^{\circ} \mathrm{C}$; IR ( $\left.\mathrm{KBr}\right)$ v $3382(\mathrm{~N}-\mathrm{H})$, 1697 (active amide), 1600 (aromatic $\mathrm{C}-\mathrm{H}$ ) $\mathrm{cm}^{-1}$; ${ }^{1} \mathrm{H} \mathrm{NMR}\left(\mathrm{CDCl}_{3}, 25^{\circ} \mathrm{C}\right) \delta 2.46\left(\mathrm{~m}, 2 \mathrm{H}, \mathrm{CH}_{2}-\mathrm{CH}_{2}\right)$, $3.65\left(\mathrm{~m}, 2 \mathrm{H}, \mathrm{N}-\mathrm{CH}_{2},\right), 4.67(\mathrm{t}, 1 \mathrm{H}, \mathrm{N}-\mathrm{H}, J=6.6$ $\mathrm{Hz}), 6.62(\mathrm{~d}, 2 \mathrm{H}, \operatorname{Ar}-H, J=8.7 \mathrm{~Hz}), 7.20-7.40(\mathrm{~m}$, $4 \mathrm{H}, \mathrm{Ar}-H), 7.84(\mathrm{~d}, 2 \mathrm{H}, \mathrm{Ar}-H, J=8.7 \mathrm{~Hz}) ;{ }^{13} \mathrm{C}$ NMR $\left(\mathrm{CDCl}_{3}, 25^{\circ} \mathrm{C}\right) \delta 30.9,35.7,110.7,112.2,112.3$, 119.6, 125.5, 125.6, 131.7, 134.8, 147.9, 153.3, 166.1 $(\mathrm{C}=\mathrm{O}), 179.5(\mathrm{C}=\mathrm{S})$; Elemental Anal. Calcd for $\mathrm{C}_{22} \mathrm{H}_{13} \mathrm{~N}_{2} \mathrm{O}_{2} \mathrm{~F}_{13} \mathrm{~S}_{1}: \mathrm{C} ; 42.87, \mathrm{H} ; 2.13, \mathrm{~N} ; 4.54, \mathrm{~F}$; 40.07, S; 5.20. Found: C; 42.77, H; 2.28, N; 4.59, F; 39.71, S; 5.12.

\section{Polymerization}

A typical polymerization procedure is as follows: All glass vessels were heated in vacuo before use, filled with and handled in a stream of dry nitrogen. Into a flask equipped with a three-way stopcock, $3(0.100 \mathrm{~g}$, $0.165 \mathrm{mmol}), \mathrm{LiCl}(0.0690 \mathrm{~g}, 1.63 \mathrm{mmol})$, and THF $(9 \mathrm{~mL})$ were placed under nitrogen. The solution was cooled to $-78^{\circ} \mathrm{C}$, and then $\mathrm{EtMgBr}(185 \mu \mathrm{L}, 0.900$ 
Poly $\left(N\right.$-fluoroalkyl benzamide) with Controlled $M_{\mathrm{n}}$ and $M_{\mathrm{w}} / M_{\mathrm{n}}$
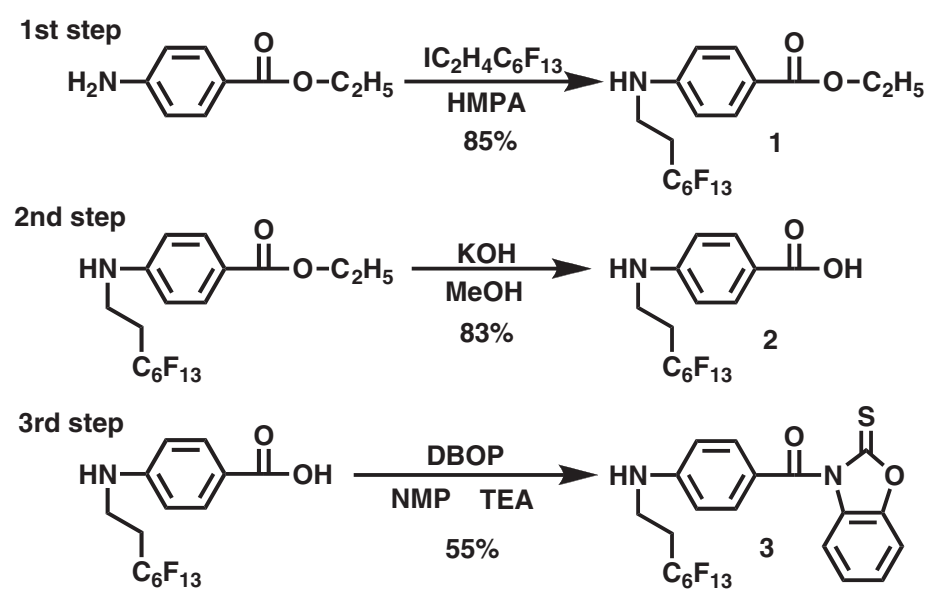

Scheme 1.

mmol) solution in THF was slowly added to give a deep yellow monomer solution. After 30 minutes at the temperature, $p$-nitrobenzoyl chloride $(50 \mu \mathrm{L}$, $0.00825 \mathrm{mmol}$ ) in THF was charged to start the polymerization. After the solution changed to orange, the temperature was raised to $-40^{\circ} \mathrm{C}$ and the solution was kept stirring for another $24 \mathrm{~h}$. The polymerization was quenched by the addition of $p$-anisidine, and the solvent was evaporated, and poured into $5 \mathrm{wt} \%$ aqueous $\mathrm{K}_{2} \mathrm{CO}_{3}$ solution $(100 \mathrm{~mL})$, filtered, washed with $\mathrm{H}_{2} \mathrm{O}$ several times, dissolved in $\mathrm{CH}_{2} \mathrm{Cl}_{2}$, dried over $\mathrm{MgSO}_{4}$, filtered, and concentrated. The remained monomer was removed by a preparative HPLC providing light-yellow powder in $81 \%$ yield. $M_{\mathrm{n}}=$ 4500, PDI $=1.17 \quad$ (GPC); $T_{\mathrm{g}}=92^{\circ} \mathrm{C}$ (DSC); IR $(\mathrm{KBr}) \vee 2923$ (C-H aromatic), 2854 (C-H aliphatic), $1650 \mathrm{~cm}^{-1}$ (amide). ${ }^{1} \mathrm{H}$ NMR $\left(\mathrm{CDCl}_{3}\right) \delta 2,45(\mathrm{~m}, 2 \mathrm{H}$, $\left.\mathrm{CH}_{2}-\mathrm{CH}_{2}\right), 4.11$ (s, 2H, N-CH $H_{2}, 6.81$ (d, $\left.2 \mathrm{H}, \mathrm{Ar}-\mathrm{H}\right)$, $7.10(\mathrm{~d}, 2 \mathrm{H}, \mathrm{Ar}-\mathrm{H}) ;{ }^{13} \mathrm{C} \mathrm{NMR}\left(\mathrm{CDCl}_{3}, 25^{\circ} \mathrm{C}\right) \delta 14.2$ $\left(\mathrm{CH}_{3}\right), 22.7,27.1,28.0,29.4,29.5,32.0,50.7\left(\mathrm{CH}_{2}\right)$, 126.9, 129.7, 134.6, 144.8, (aromatic), 169.0 (amide); Elemental Anal. Calcd: C; 39.38, H; 1.81, N; 3.22, F; 51.58. Found: C; 40.11, H; 1.93, N; 3.24; F; 48.90.

\section{RESULTS AND DISCUSSION}

\section{Monomer Synthesis}

Various types of polymers having $N$-fluoroalkyl [(Rf): $\left.\left(\mathrm{CF}_{2}\right)_{\mathrm{n}-1} \mathrm{CF}_{3}\right]$ groups are reported, and the length of $\mathrm{Rf}$ chains is known to change the surface property. ${ }^{12}$ In general, a polymer having $\operatorname{Rf}(n>8)$ chains shows stable low energy surface due to the crystallinity or liquid crystallinity. ${ }^{12 \mathrm{c}}$ However, introduction of longer $\mathrm{Rf}$ chains into a polymer backbone extremely decreases the solubility and compatibility to the other materials. Thus, we decided to introduce the $\operatorname{Rf}(n=6)$ unit onto the polyamide across an ethylene spacer.

As we described in Introduction, a polyamide with the controlled MW and PDI was successfully prepared, in which the selection of the activator (base) is critical to avoid conventional polycondensation. Recently, lithium hexamethyldisilazide (LiHMDS) was found to be effective to control the polycondensation for 4- $\mathrm{N}$-alkylaminobenzoic acid methyl ester at $0^{\circ} \mathrm{C}$ within minutes; ${ }^{5 \mathrm{c}}$ thus we first investigated the polycondensation of $\mathbf{1}$ using this base. Neither an equivalent of the base nor the excess amounts of the base with an initiator afforded the corresponding polymer, but gave black materials whose structure could not be identified. The ${ }^{1} \mathrm{H}$ NMR spectrum of the resulting black powder showed many signals in addition to the residual 1, and the spectrum were not able to identify at all. The $M_{\mathrm{n}}$ of the compounds was below 1,000, which is far from the expected value of 10,000 . Therefore, the new monomer $\mathbf{3}$ was prepared from $\mathbf{1}$ in threesteps (Scheme 1). EtMgBr, which was employed for the controlled polycondensation of 4- $\mathrm{N}$-octylamino benzoylbenzoxazolin-2-thione we reported, ${ }^{5 b}$ was used for the polycondensation of $\mathbf{3}$. The structure of 3 was assigned by IR and NMR spectroscopy, and elemental analysis. The IR spectrum of $\mathbf{4}$ exhibited the characteristic absorption of the $\mathrm{C}=\mathrm{O}$ vibration at $1697 \mathrm{~cm}^{-1}$. Figure 1 shows the ${ }^{1} \mathrm{H}$ NMR spectrum with assignments of all peaks, where the characteristic signal due to the $\mathrm{NH}$ proton appears at $4.7 \mathrm{ppm}$. Furthermore, signals assignable to the carbonyl and the $\mathrm{C}=\mathrm{S}$ carbons appeared at 166.1 and $179.5 \mathrm{ppm}$, respectively, in the ${ }^{13} \mathrm{C}$ NMR spectrum. The elemental analysis also supported the formation of $\mathbf{3}$.

\section{Polycondensation}

The polycondensation was first performed using the similar conditions in literature: ${ }^{\mathrm{b}} \mathrm{b}$ the initial monomer concentration $[3]_{0}=0.15 \mathrm{~mol} / \mathrm{L}$ and 15 equiv of $\mathrm{LiCl}$ to $\mathbf{3}$, where $\mathrm{EtMgBr}$ was used as the base (Scheme 2). The results are shown in Figure 2. The $M_{\mathrm{n}}$ of $\operatorname{poly}(N-$ fluoroalkyl benzamide) 4 increases with increasing the 


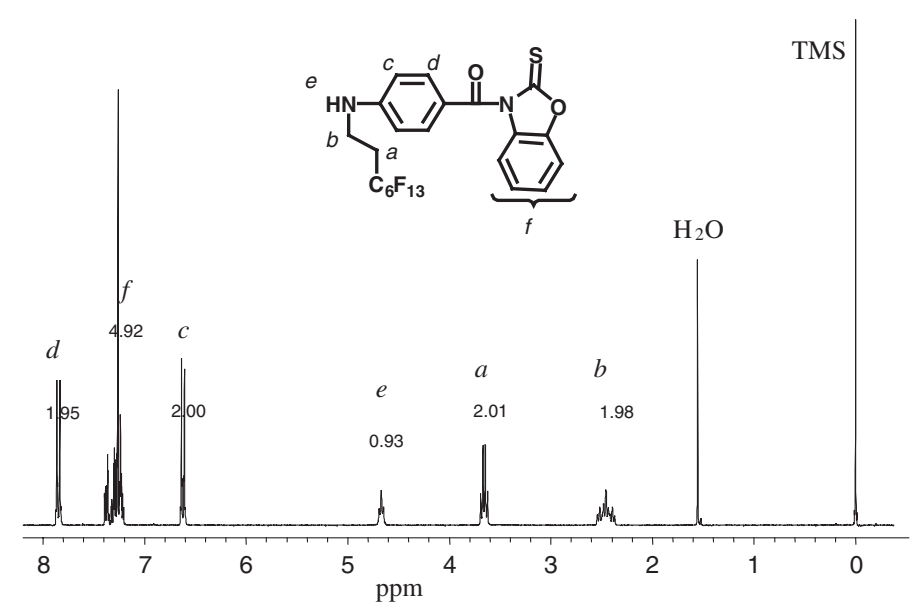

Figure 1. ${ }^{1} \mathrm{H}$ NMR spectrum of 3 .
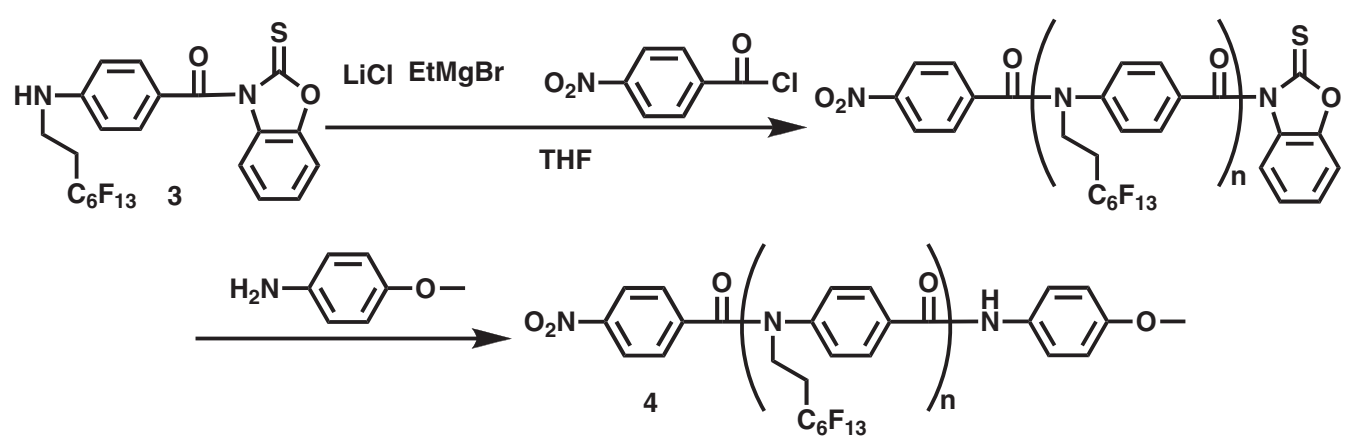

Scheme 2.

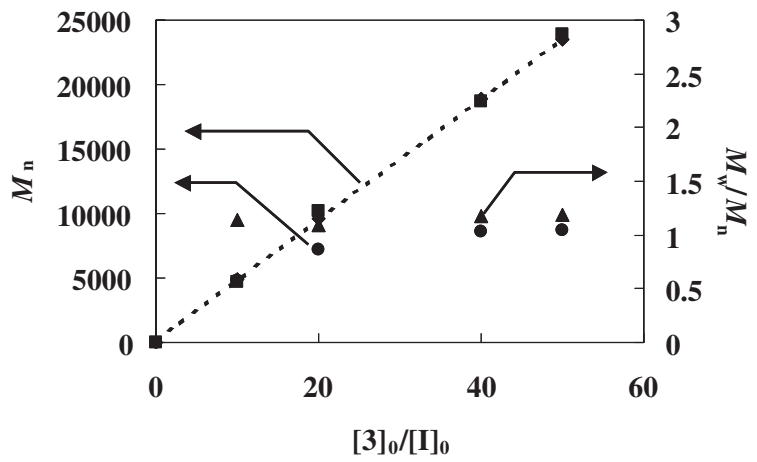

Figure 2. Relationship between $M_{\mathrm{n}(\mathrm{NMR})}, M_{\mathrm{n}(\mathrm{calc})}, M_{\mathrm{w}} / M_{\mathrm{n}}$, and $[3]_{0} /[\mathrm{I}]_{0}$ for the polymerization in a) $[3]_{0}=0.15 \mathrm{~mol} / \mathrm{L}$, and b) $[3]_{0}=0.018 \mathrm{~mol} / \mathrm{L}$. $M_{\mathrm{n}(\mathrm{NMR})}$ for condition a) is marked as $\bullet, M_{\mathrm{n}(\mathrm{NMR})}$ and $M_{\mathrm{w}} / M_{\mathrm{n}}$ for condition b) is marked as $\boldsymbol{\square}$ and $\boldsymbol{\Delta}$, respectively. $M_{\mathrm{n}(\mathrm{calc})}$ is illustrated as a dotted line.

feed ratio of $\mathbf{3}$ to the initiator up to 10, but the heavy deviation is found after that. Polymer $\mathbf{4}$ showed worse solubility in organic solvents than poly( $N$-octyl benzamide) obtained from 4- $\mathrm{N}$-octylaminobenzoic acid derivative; thus the deviation of the $M_{\mathrm{n}}$ might be from the precipitation of the polymer produced in the conditions. Thus, the polycondensation was carried out in more diluted conditions $\left([3]_{0}=0.018 \mathrm{~mol} / \mathrm{L}\right)$. The polymers with the small PDI are quantitatively ob-
Table I. Synthesis of polyamide

\begin{tabular}{cccccc}
\hline Run & {$[3]_{0} /[\mathrm{I}]_{0}$} & Conv $(\%)^{\mathrm{b}}$ & $M_{\mathrm{n}}(\mathrm{calc})$ & $M_{\mathrm{n}}(\mathrm{NMR})^{\mathrm{b}}$ & $\mathrm{PD}^{\mathrm{c}}$ \\
\hline 1 & 10 & 94 & 4,900 & 4,700 & 1.14 \\
2 & 20 & 96 & 9,600 & 10,200 & 1.09 \\
3 & 40 & 98 & 18,900 & 18,700 & 1.18 \\
4 & 50 & 95 & 23,500 & 23,900 & 1.19 \\
\hline \multicolumn{5}{c}{${ }^{\mathrm{a}}$ Conditions: $[3]_{0}=0.018 \mathrm{M}}$,
\end{tabular}
$[3]_{0}=1.0$, in $\mathrm{THF}$ at $-40{ }^{\circ} \mathrm{C}$ for $24 \mathrm{~h}$. ${ }^{\mathrm{b}}$ Determined by ${ }^{1} \mathrm{H}$ NMR. ${ }^{\mathrm{c}}$ Determined by $\mathrm{GPC}\left(\mathrm{CHCl}_{3}\right.$, PSt standard $)$.

tained, and the $M_{\mathrm{n}}$ values are very close to the expected one (Table I). As shown in Figure 2, the $M_{\mathrm{n}}$ of $\mathbf{4}$ increases linearly with increasing the feed ratio of $\mathbf{3}$ to the initiator, while maintaining the small PDI. Polymer 4 was quenched by the addition of $p$-anisidine as described in Experimental Section.

The structure of $\mathbf{4}$ was characterized by IR, ${ }^{1} \mathrm{H}$ and ${ }^{13} \mathrm{C}$ NMR spectroscopy, and elemental analysis. The characteristic absorption of the $\mathrm{C}=\mathrm{O}$ vibration was still observed at $1650 \mathrm{~cm}^{-1}$ in the IR spectrum, and in the ${ }^{13} \mathrm{C}$ NMR spectrum, the signal assignable to the $\mathrm{C}=\mathrm{S}$ carbonyl completely disappeared, while the signal assignable to aromatic amide was observed at $169.0 \mathrm{ppm}$. In the ${ }^{1} \mathrm{H}$ NMR spectrum as shown in 


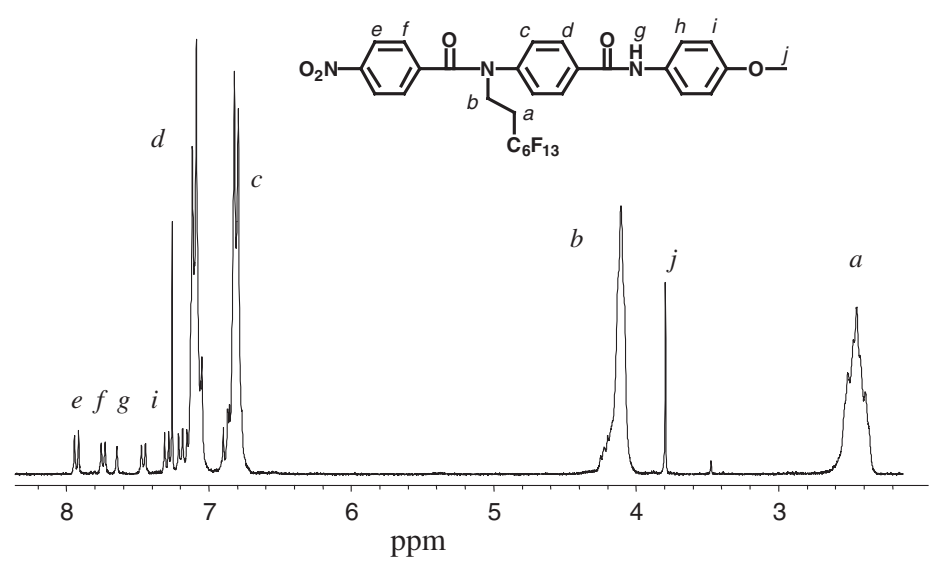

Figure 3. ${ }^{1} \mathrm{H}$ NMR spectrum of $\mathbf{4}$ (run 2 in Table I).

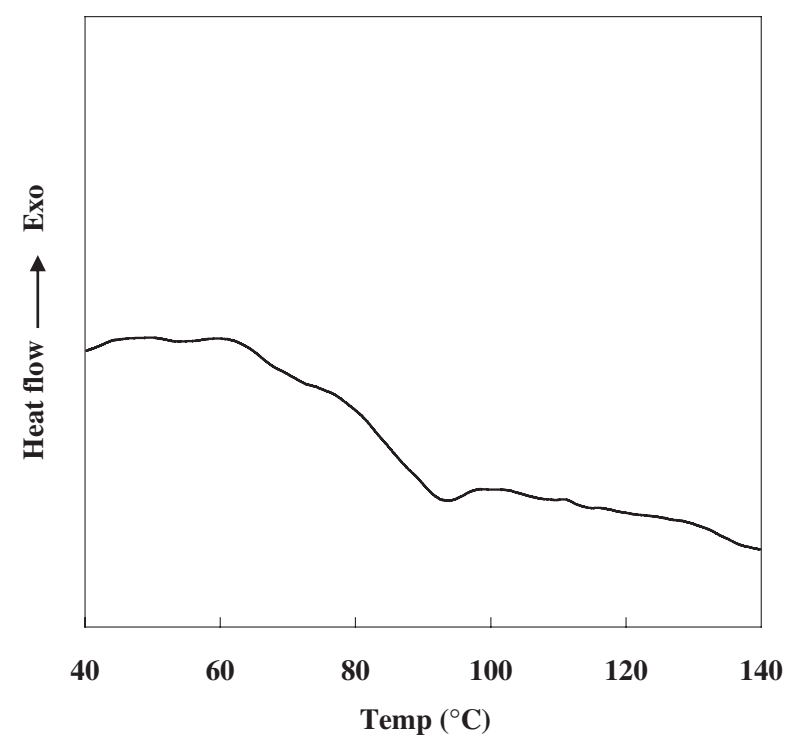

Figure 4. DSC $2^{\text {nd }}$-profile of $\mathbf{4}$ (run 2 in Table I).

Figure 3, in addition to the signals assignable to aromatic protons of the polymer main chain around 6.7-7.2 ppm, signals due to the initiating and terminal groups are observed at 7.9 and $3.8 \mathrm{ppm}$, respectively. The calculated $M_{\mathrm{n}(\mathrm{NMR})}$ from the integration of signals $e$ and $c$ was 10,200 , which is close to the expected $M_{\mathrm{n}}$ of 9,600 from the feed ratio of $\mathbf{3}$ and the initiator. The integration ratio of the signals $e$ and $j$ is 2 to 3 , indicating that all polycondensation is initiated with $p$ nitrobenzoyl chloride and terminated with $p$-anisidine.

Figure 4 shows the DSC $2^{\text {nd }}$ profile of 4 (run 2 in Table I) under nitrogen. An endothermic shift corresponding to the glass transition temperature $\left(T_{\mathrm{g}}\right)$ is observed at $92^{\circ} \mathrm{C}$, which is higher than poly $(N$-octyl benzamide $)\left(38^{\circ} \mathrm{C}, M_{\mathrm{n}}=8,000\right.$, PDI $\left.=1.21\right)$. The higher glass transition is attributed to the larger size of fluorine compared to hydrogen, resulting in making the side chains be more rigid. Thermogravimetric analysis of $\mathbf{4}$ showed that the 5\% weight loss temperature was $380^{\circ} \mathrm{C}$.
Polymer $\mathbf{4}$ has the $\mathrm{Rf}$ chain on the side; thus the film would show low energy surface due to surface accumulation of Rf chains. To evaluate the surface character, the contact angle of the annealed film was measured using a water droplet. The contact angle of the polymer film was $105^{\circ}$ (run 2 in Table I), which is higher than poly $(N$-octyl benzamide) (contact angle $=$ $\left.91.0^{\circ}\right) .{ }^{12}$ If the $\mathrm{Rf}$ groups are assembled in high density and cover the polymer surface, the contact angle value will be $120^{\circ} .{ }^{13}$ The rather lower contact angle of $\mathbf{4}$ indicates that the $\mathrm{Rf}$ moieties on the amide group face the surface, but are not aligned finely due to their low density on the polyamide backbone and rather the short $\mathrm{Rf}$ chain of $\mathrm{n}=6$. In the DSC measurement of the polymer sample both in film and powder, no endothermic peak due to melting except for the $T_{\mathrm{g}}$ at $92{ }^{\circ} \mathrm{C}$ was observed, which indicates that the Rf chain in this polymer does not crystallized at all. Anyhow, the higher contact angle value than poly( $N$-octyl benzamide) suggests that phase segregation could be observed when the block copolymer is prepared from $\mathbf{3}$ and $N$-octyl benzamide.

\section{SUMMARY}

We have demonstrated the preparation of $\operatorname{poly}(N-$ fluoroalkyl benzamide) 4 with the controlled molecular weight (MW) and polydispersity index (PDI) via the chain-growth polycondensation of 3 . The MW and PDI were able to control up to the $M_{\mathrm{n}}$ of 24,000 under relatively diluted conditions to avoid the precipitation of the resulting polymer. Poly( $N$-fluoroalkyl benzamide) 4 showed the $T_{\mathrm{g}}$ of $92^{\circ} \mathrm{C}$, which is higher than that of poly $\left(N\right.$-octyl benzamide) $\left(T_{\mathrm{g}}\right.$ of $\left.38^{\circ} \mathrm{C}\right)$. The film spin cast from 4 in THF showed a higher contact angle against a water droplet than the poly( $N$-octyl benzamide) film. Therefore, monomer $\mathbf{3}$ is a good candidate for the synthesis of an amphiphilic block copolymer to investigate the phase separation behavior of a condensation block copolymer. 


\section{REFERENCES}

1. a) G. M. Whitesides, J. P. Mathais, and C. Seto, Science, 254, 1312 (1991).

b) C. R. Martin, Science, 266, 1961 (1994).

c) A. Firouzi, D. Kumar, L. M. Bull, T. Besier, P. Sieger, W. Huo, S. A. Walker, J. A. Zasadzinski, C. Glinka, J. Nicol, D. Margolese, G. D. Stucky, and B. F. Chmelka, Science, 267, 1138 (1995).

2. a) A. Hirao, M. Hayashi, S. Loykulnant, K. Sugiyama, S. W. Ryu, N. Haraguchi, A. Matsuo, and T. Higashihara, Prog. Polym. Sci., 30, 111 (2005).

b) C. J. Allender, K. R. Brain, and C. M. Heard, in "Progress in Medical Chemistry," 2nd ed, F. D. King and A. W. Oxford, Ed., Elsevier Science, Amsterdam, 1999, vol. 36, chap. 6, p 235.

3. a) M. Szwark, M. V. Beylen, "Inonic Polymerization and Living Polymers," Chapman \& Hall, New York, 1993.

b) Y. Miura, K. Satoh, M. Kamigaito, and Y. Okamoto, Polym. J., 38, 930 (2006).

4. H. Yamakawa and H. Miyata, "High Performance Thermoplastic Aramid Elastomers: Synthesis, Properties, and Applications" in "Handbook of Condensation Thermoplastic Elastomers," S. Fakirov, Ed., WILEY-VCH, Weinheim, 2005, chap. 5, p. 141.

5. a) T. Yokozawa, T. Asai, R. Sugi, S. Ishigooka, and S.
Hiraoka, J. Am. Chem. Soc., 122, 8313 (2000).

b) Y. Shibasaki, T. Araki, and M. Ueda, Polym. J., 34, 261 (2002).

c) R. Sugi, A. Yokoyama, T. Furuyama, M. Uchiyama, and T. Yokozawa, J. Am. Chem. Soc., 127, 10172 (2005).

6. T. Yokozawa, T. Taniguchi, Y. Suzuki, and A. Yokoyama, J. Polym. Sci., Part A: Polym. Chem., 40, 3460 (2002).

7. Y. Shibasaki, T. Araki, R. Nagahata, and M. Ueda, Eur. Polym. J., 41, 2428 (2005).

8. T. Yokozawa, M. Ogawa, A. Sekino, R. Sugi, and A. Yokoyama, J. Am. Chem. Soc., 124, 15158 (2002).

9. K. Iwashita, A. Yokoyama, and T. Yokozawa, J. Polym. Sci., Part A: Polym. Chem., 43, 4109 (2005).

10. M. C. Iovu, E. E. Sheina, R. R. Gill, and R. D. McCullough, Macromolecules, 38, 8649 (2005).

11. a) L. A. Wall, “Fluoropolymers," Wiley, New York, 1972. b) S. V. Gangal, in "Encyclopedia of polymer science and engineering," Wiley, New York, 1989, vol. 16, p. 577-600. c) M. Yamabe, Makromol. Chem. Macromol. Symp., 64, 11 (1992).

12. a) J. Genzer, E. Sivaniah, E. J. Kramer, J. Wang, H. Korner, M. Xiang, K. Char, C. K. Ober, B. M. DeKoven, R. A. Bubeck, M. K. Chaudhury, S. Sambasivan, and D. A. Fischer, Macromolecules, 33, 1882 (2000).

b) Y. Saegusa and T. Koizumi, Polym. J., 37, 399 (2005).

c) S. V. Arehart and C. Pugh, J. Am. Chem. Soc., 119, 3027 (1997).

13. J. Wang and C. K. Ober, Macromolecules, 30, 7560 (1997). 